Brit. Heart f., 1967, 29, 801.

\title{
Arterial Blood Supply of the Human Sinus Node*
}

\author{
L. VERHAEGHE AND L. VAN DER HAUWAERT
}

\author{
From the Department of Anatomy (Vesalius Institute) of the University of Louvain, Belgium
}

The gross anatomy of the artery irrigating the sinus node has been described in a few studies dealing with the structure of the node in general (Hudson, 1960; James, 1961). A semi-quantitative account, mainly concerned with the density of the capillary and precapillary network in the node, has recently been presented by Clarke (1965). Apart from some general remarks, however, little reference is found to the course of the artery and its pattern of ramification within the node. The present study, based on a combination of post-mortem angiography and histology, was undertaken to outline the arterial distribution and to evaluate the vascular density in the node of Keith and Flack.

\section{Methods}

Ten normal hearts, from patients with ages ranging from 19 to 79 years, were examined. The coronary orifices were cannulated and radiopaque material was injected by hand under controlled pressure of 60 to $90 \mathrm{~mm}$. Hg. A suspension of 45 parts barium sulphate (Alubar Wander) and 55 parts 4 per cent formol, with a particulate diameter of $2 \mu$ and a viscosity of 0,314 poise (according to the Hoeppler method), was used. This medium penetrated uniformly to precapillary arterioles of approximately $20 \mu$, without filling the capillaries.

$X$-ray films of the intact heart were taken in various incidences on Gevaert Structurix D2 plates. The distance was $150 \mathrm{~cm}$., exposure time $20 \mathrm{sec} . \mathrm{kV}$ being set at 50 and $\mathrm{m} \AA$ at 30 . Subsequently the heart was fixed in 10 per cent formol and preserved in a bath of equal parts of glycerol and $80^{\circ}$ alcohol.

For detailed study, the right atrium, including the interatrial septum and the superior cava-atrial junction, was dissected from the rest of the heart. This yielded a funnel-shaped preparation. Starting from the posteromedial corner of the junction between the superior vena cava and the right atrium, a vertical incision was made through the dorsal wall of the atrium. This allowed unrolling of the atrium in one plane. The flap was then divided into three roughly equal parts of which the

Received March 16, 1967

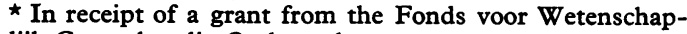
pelijk Geneeskundig Onderzoek. middle one, corresponding to the antero-lateral aspect of the atrium, was expected to contain the sinus node. Indeed with some experience it is usually possible to locate the node from macroscopic landmarks (Hudson, 1960). Numerous $x$-ray films were taken of these flattened preparations from different angles, before and after embedding in paraffin.

For histological studies, the block containing the sinus node was serially sectioned at $7 \mu$ and every 25 th section was retained and stained with hæmatoxylin, eosin, and safranin, or with Masson trichrome. Care was taken to cut the block perpendicular to the course of the sinus node artery, which had previously been visualized on the $x$-ray films. As the block was sectioned the remaining part of it was $x$-rayed regularly at approximately $5 \mathrm{~mm}$. intervals. These pictures and the corresponding sections were given numbers and used as points of reference when the histological slides were correlated with the films. For this purpose a magnified $(\times 5)$ photograph of the coronary angiogram of the entire sinus node region was used. Vertical lines, corresponding to the numbered reference sections, were drawn on this "map" (Fig. 1), By means of these points of reference all arteries and larger arterioles visible on the photograph were easily identified in the histological slides. Special attention was paid to the anatomical relation between the arteries and the specific sinus node tissue. The borders of the node were thus accurately localized in relation to the arteries and arterioles in each particular section and transferred to the photograph. Histological study of some 200 slides of each sinus node region and their correlation with magnified photographs of its coronary system made it possible to determine exactly which coronary arteries were lying inside the node, and to trace all branches from their origin to precapillary level. The final result was a reconstruction drawing demonstrating the coronary system of the sinus node and the adjacent area (Fig. 2 and 3).

In a quantitative study the density of the arterial blood supply to the sinus node was estimated. For every heart 10 transverse sections, equally distributed over the length of the node, were studied. The total cross-sectional area of the arterial lumina was planimetrically measured and expressed as a percentage of the total surface of the sinus node (Fig. 4). Based on these 10 values the mean percentage for the entire node 801 


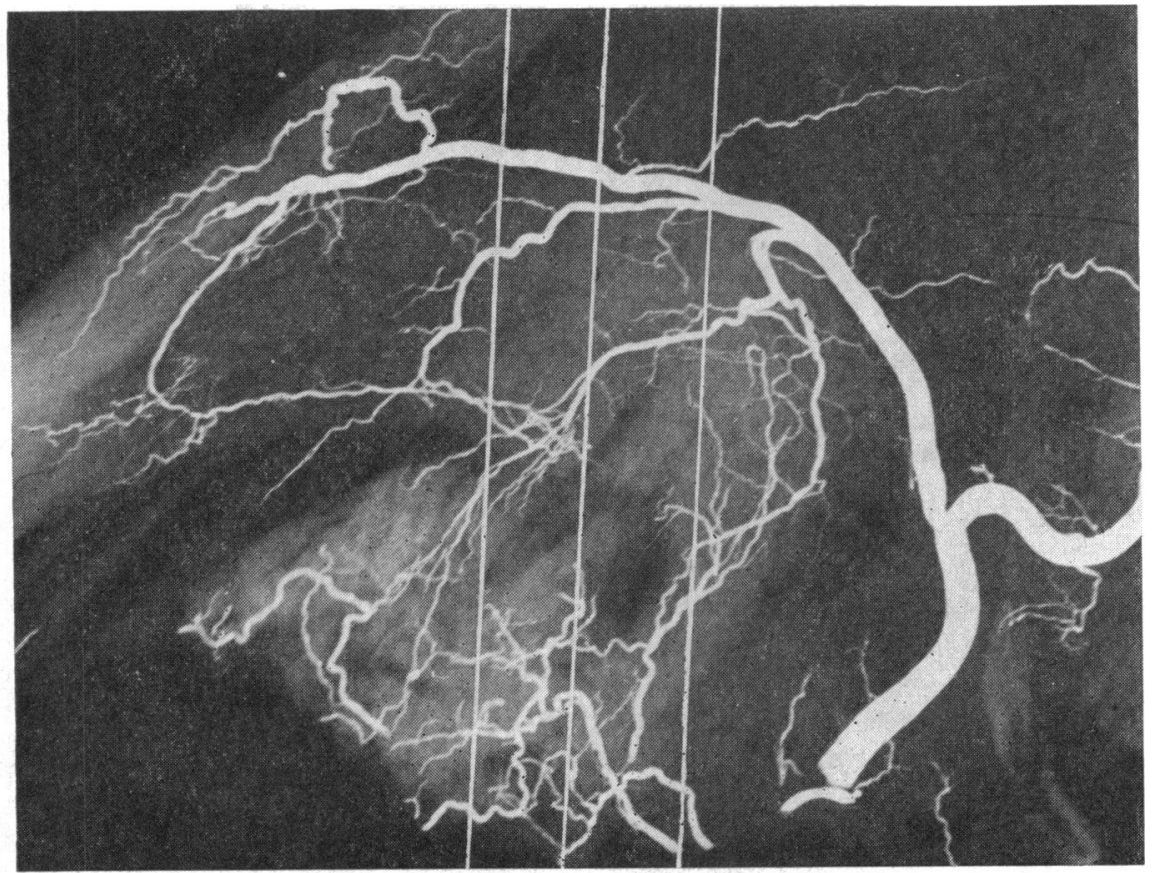

FIG. 1.-Coronary angiogram of the sinus node region (approx. $\times 5$ ). The vertical lines correspond to reference sections that were used as landmarks in the comparison of histological slides with angiographic findings (see text).

pressing arterial density, was calculated for an adjacent part of the atrial wall included in the same slides. The use of a drawing tube made it possible to project onto the atrial wall in the caudal part of the paranodal tissue, an area of equal shape and size to the node. In this area, also, the arterial lumina were planimetrically measured, summed up, and likewise expressed as a percentage of the total surface.

\section{RESULTS}

The sinus node artery (ramus ostii cavæ superioris) originated from the left coronary artery in 5 cases, from the right in 4 cases, and from both coronary arteries in 1 case (Table). When its origin was left-sided, it always arose from the left circumflex coronary artery. In all hearts the sinus node

TABLE

SINUS NODE ARTERY (SNA): MAIN ANATOMICAL FINDINGS IN 10 NORMAL HEARTS

\begin{tabular}{|c|c|c|c|c|c|c|}
\hline $\begin{array}{r}1 \\
2 \\
3 \\
4 \\
5 \\
6 \\
7 \\
8 \\
9 \\
10\end{array}$ & $\begin{array}{c}\text { Right } \\
\text { Left } \\
\text { Right } \\
\text { Right and left } \\
\text { Right } \\
\text { Left } \\
\text { Left } \\
\text { Right } \\
\text { Left } \\
\text { Left }\end{array}$ & $\begin{array}{c}\text { Clockwise } \\
\text { Clockwise } \\
\text { Counterclockwise } \\
\text { Right: counterclock- } \\
\text { wise; left: clockwise } \\
\text { Counterclockwise } \\
\text { Counterclockwise } \\
\text { Clockwise } \\
\text { Counterclockwise } \\
\text { Clockwise } \\
\text { Counterclockwise }\end{array}$ & $\begin{array}{c}1 \cdot 3 \\
1 \cdot 2 \\
1 \cdot 4 \\
\text { Right: } 0 \cdot 8 \\
\text { Left: } 0 \cdot 8 \\
1 \cdot 0 \\
1 \cdot 0 \\
1 \cdot 2 \\
1 \cdot 0 \\
1 \cdot 2 \\
1 \cdot 5\end{array}$ & $\begin{array}{c}20 \\
5 \\
18 \\
\text { Right: } 5 \\
\text { Left: } 10 \\
13 \\
6 \\
12 \\
19 \\
27 \\
12\end{array}$ & $\begin{array}{l}10 \cdot 5 \\
19 \cdot 0 \\
12 \cdot 6 \\
14 \cdot 5 \\
11 \cdot 2 \\
12 \cdot 7 \\
20 \cdot 9 \\
9 \cdot 3 \\
12 \cdot 4 \\
17 \cdot 8\end{array}$ & $\begin{array}{l}1 \cdot 4 \\
1 \cdot 8 \\
1 \cdot 7 \\
1 \cdot 5 \\
1 \cdot 7 \\
2 \cdot 1 \\
2 \cdot 0 \\
1 \cdot 4 \\
3 \cdot 0 \\
1 \cdot 4\end{array}$ \\
\hline Mean & & & 1.0 & $13 \cdot 4$ & $14 \cdot 1$ & $1 \cdot 8$ \\
\hline
\end{tabular}

$\star$ Viewed from above.

+ Percentage of the cross-sectional area of the sinus node occupied by arterial lumina. 


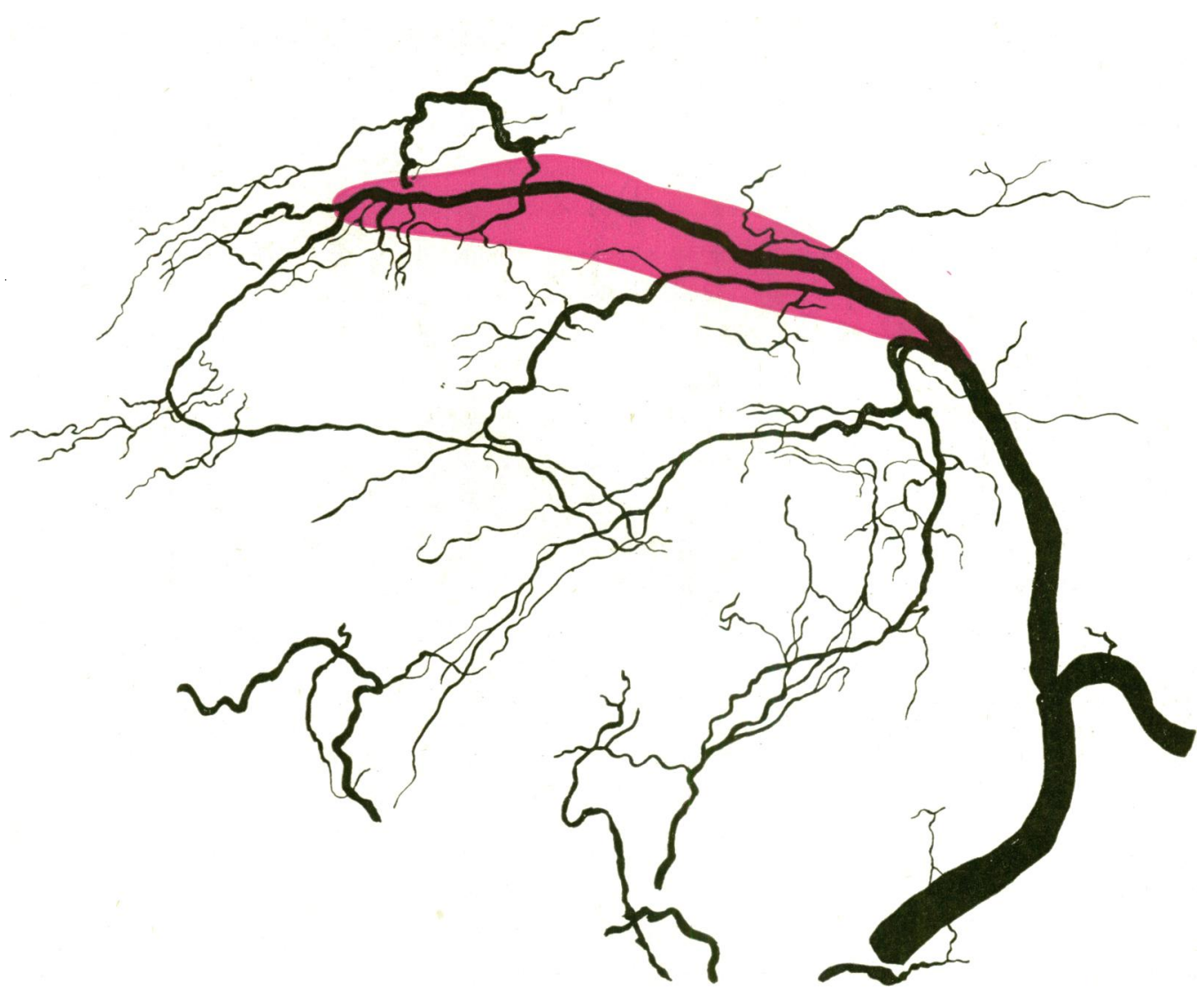

FIG. 2.-Reconstructive drawing of the sinus node artery (Case 3, same heart as shown in Fig. 1). The sinus node tissue is red. It will be noted that the artery is situated in the middle of the node and that it is completely enveloped by conductive tissue. A similar central course was found in 7 of the 10 hearts examined.

artery was the largest atrial coronary branch. Its hæmodynamic importance is further illustrated by measurements of its diameter within $5 \mathrm{~mm}$. from the origin. The average diameter was $1.0 \mathrm{~mm}$. (range 0.8 to $1.5 \mathrm{~mm}$.), while the average diameter of the main coronary artery, just proximal to the origin of the sinus node artery, was $3.3 \mathrm{~mm}$. The origin was always from the first segment of the coronary artery, and the average distance from the coronary ostium was only $13.4 \mathrm{~mm}$. (range 5 to $27 \mathrm{~mm}$.). The artery coursed upwards towards the superior vena cava and encircled its orifice either clockwise (in 4 cases) or counterclockwise (5 cases) when viewed from above. In the one instance where the origin was bilateral, the branch from the left coronary coursed clockwise and the one from the right coronary artery counterclockwise.

Within the sinus node a fairly uniform pattern of blood supply was found in 7 of the 10 hearts. In these the artery entered one pole of the spindleshaped node, occupied its central part, and left it at the opposite pole (Fig. 2). In two of these nodes the artery divided into two almost equally large branches which ran a parallel course.

In 3 hearts the artery entered the node laterally. In one it bifurcated immediately into two major branches each of which ran towards one of the extremes (Fig. 3). In the other two the arterial ramification was completely asymmetrical, the artery entering the node laterally and giving rise to several branches irregularly distributed throughout the node.

In all instances the coronary ramifications were more abundant and ran a more parallel course to the major vessel than in the adjacent free atrial wall. Numerous small branches left the sinus node to terminate in the atrial wall or to anastomose with other atrial coronary arterioles. Large anastomoses, 


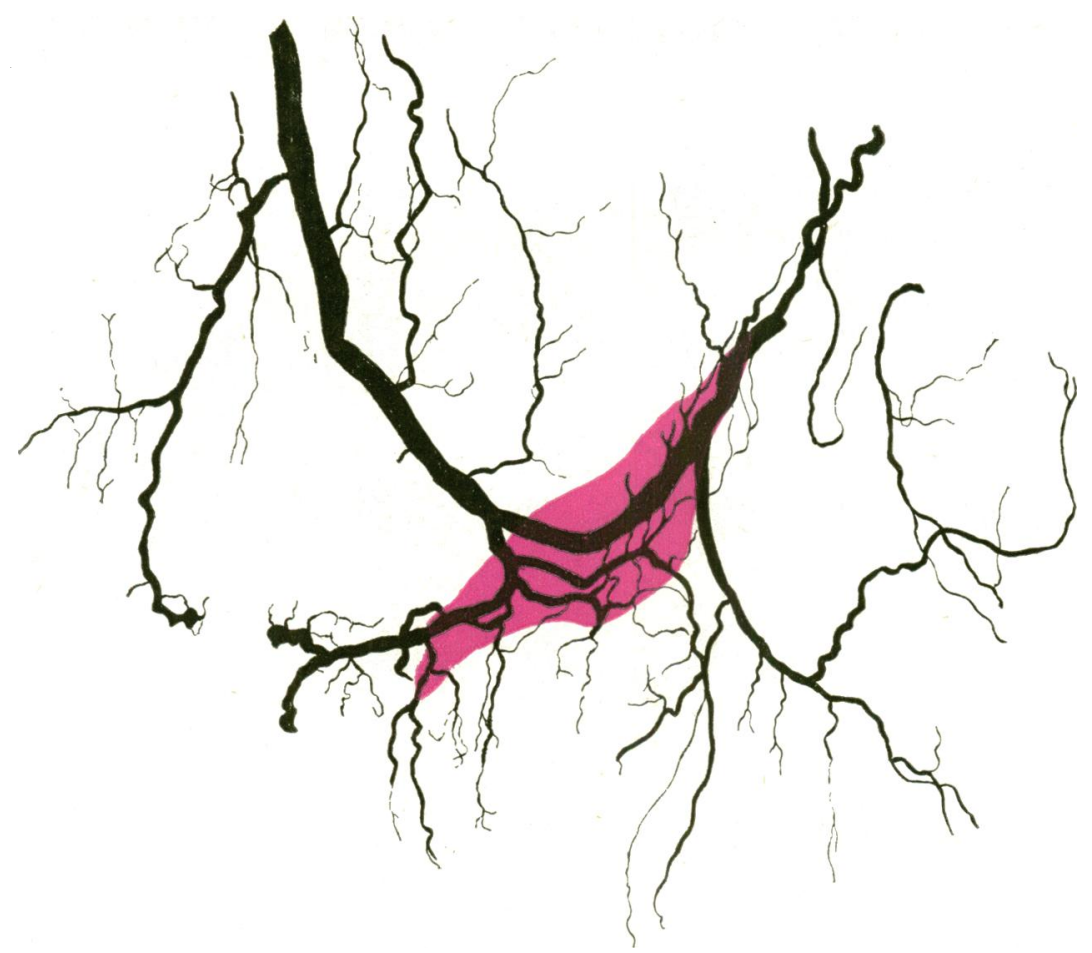

FIG. 3.-Uncommon type of arterial distribution within the sinus node (Case 10). The artery enters the node laterally and bifurcates into two branches, each directed towards one of the extremes of the node.

Note the marked arterial density and the intimate relation between the arteries and the nodal tissue.

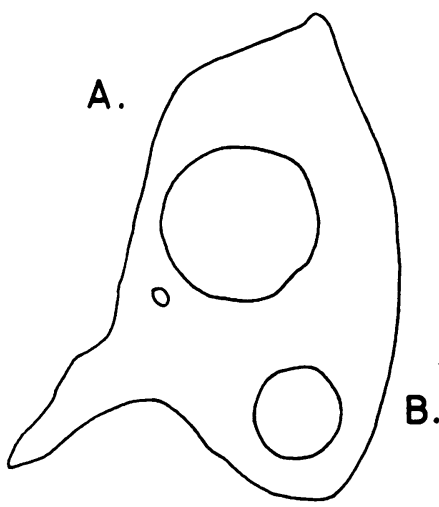

$24.1 \%$

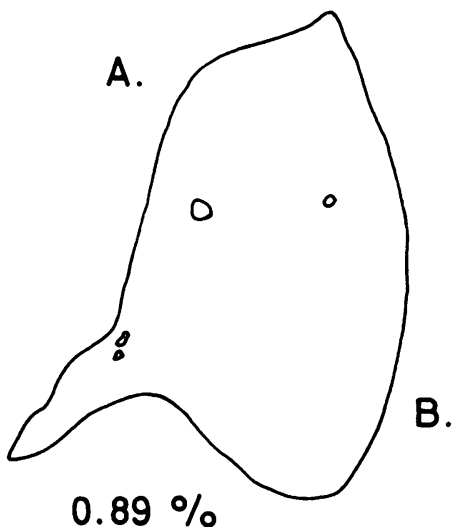

$0.89 \%$

FIG. 4.-Schematic drawing of a cross-section through the sinus node and its arteries (left) and through a part of the free atrial wall (right). In all hearts a region adjacent to the node, and of equal surface and shape, was arbitrarily designated in the atrial wall immediately caudal to the node. It served as reference in a quantitative study of the arterial density. In the example shown, the sections correspond to the middle vertical line drawn on the angiogram represented in Fig. 1. The arterial lumina occupy a much larger portion of the cross-sectional surface of the sinus node than of the free atrial wall. The figures underneath express the percentage of the planimetrically determined cross-sectional area occupied by arterial lumina. $\mathrm{A}=$ epicardial side, $\mathrm{B}=$ endocardial side. 
however, were rare. It is remarkable that in most preparations the diameter of the artery tapered very little as its course was followed through the node.

The results of the planimetric measurements are presented in the Table. It will be seen that in the 10 hearts examined an average of 14 per cent of the total cross-sectional area of the sinus node was made up by arterial and arteriolar lumina. For an equally large zone of free atrial wall, caudal to the node and immediately adjacent to it, the mean value was only 2 per cent.

\section{Discussion}

Since its original description by Keith and Flack (1907), the sinus node has been known to have a special arterial blood supply. The present gross anatomical findings are in accordance with the studies of James and Burch (1958) and James (1961), who made use of an injection and corrosion technique to outline the coronary arteries. As pointed out by these authors, the sinus node artery is the largest atrial coronary branch; it originates from the right or left coronary artery and encircles the orifice of the superior vena cava in either a clockwise or a counterclockwise direction.

So far, the exact course of the sinus node artery and its pattern of ramification within the node have not been studied systematically. In a general way it has been stated that the artery is commonly located near the centre of the node and that there are sometimes two branches of equal size (James, 1961). Hudson (1960) noted that the node contained one large artery or two or more branches. $\mathrm{He}$ also commented on the abundance of arterioles and capillaries. In the present study a characteristic pattern of arterial blood supply was found in 7 of the 10 hearts. The sinus node artery coursed in the centre of the nodal tissue and gave rise to multiple small branches that often remained parallel to the major vessel. More complicated patterns were encountered in 3 instances.

The unusual density of the arterial blood supply to the sinus node is illustrated by the observation that approximately one-seventh (14\%) of the crosssectional area of the node is occupied by arteriolar lumina. This is about eight times more than in the adjacent free atrial wall.

The extensiveness of the blood supply to the sinus node has also been demonstrated by Clarke (1965). Because of the small particulate diameter $(0.5 \mu)$ of the radiopaque material he employed, mainly capillaries and precapillary arterioles were injected. As the purpose of our study was to visualize the arterial and arteriolar ramifications, the particulate diameter and viscosity were chosen so that the suspension would not enter the capillaries. It is clear, therefore, that a different vascular territory, with some overlapping in the arteriolar region, was explored. Both studies are, however, in complete accord and supplement each other.

The abundant arterial supply to the sinus node must in some way be related to its function. In a teleological sense one might speculate that pacemaking is a highly critical function that needs an excellent blood supply in all circumstances. It is also possible, though still unproven, that the metabolic requirements of pacemaking cells are higher than those of the surrounding myocardium. In addition to its nutritive function, the arterial system may be an important link in setting off automatic nervous impulses (James, 1961). Indeed the sinus node contains extensive nervous plexuses (Rossi, 1966) that might easily be triggered by changes of arterial pressure, heart rate, electrolytes, or acid base balance. In this connexion it may be relevant that the sinus node artery originates close to the coronary orifice, that it is completely enveloped by specific nodal tissue, and that its diameter tapers only slightly during its course through the node. These anatomical characteristics all favour the transmission of "pulsatile information" from the aorta to the nodal cells and their nervous endings. Furthermore, it has recently been demonstrated (Ryback and Mizeres, 1965) that the sinus node artery loses the outer longitudinal muscle layer of its media and that the adventitia is replaced by its specific nodal cells as the artery proceeds to enter the node. Thus, the histological structure of its wall makes this artery even more appropriate for transmission of mechanical and chemical impulses.

\section{SUMMARY}

The arterial blood supply of the human sinus node has been studied by correlating post-mortem coronary angiograms with histological sections. The method enables identification of all coronary arteries and larger arterioles in relation to the specific conductive tissue. A fairly uniform pattern of arterial distribution is described. The arterial density, estimated by planimetric measurements of the arterial lumina, was found to be approximately eight times greater within the sinus node than in the adjacent free atrial wall. The possible functional significance of these anatomical findings is briefly discussed.

We wish to thank Professor J. Bonte for his stimulating help with this investigation and Dr. Hamish Watson for assisting with the manuscript. We gratefully acknowledge the technical help of Mrs. M. Hämmerle-Massaer and $\mathrm{Mr}$. R. Stroobandt. 


\section{REFERENCES}

Clarke, J. A. (1965). An $x$-ray microscopic study of the arterial supply to the conducting system of the human heart. Brit. Heart F., 27, 879.

Hudson, R. E. B. (1960). The human pacemaker and its pathology. Brit. Heart f., 22, 153.

James, T. N. (1961). Anatomy of the human sinus node. Anat. Rec., 141, 109.
- , and Burch, G. E. (1958). The atrial coronary arteries in man. Circulation, 17, 90.

Keith, A., and Flack, M. (1907). The form and nature of the muscular connections between the primary divisions of the vertebrate heart. F. Anat. Physiol. (Lond.), 41, 172.

Rossi, L. (1966). Conducting and nervous system of the heart in atrial arrhythmias. A clinicopathological study of 33 cases. Acta cardiol. (Brux.), 21, 34.

Ryback, R., and Mizeres, N. J. (1965). The sinus node artery in man. Anat. Rec., 153, 23.

The following papers will appear in an early issue of this fournal:

Congenital Quadricuspid Pulmonary Valve. By ANTHONY ENOCH

Hæmodynamic Effects of Isopropylnoradrenaline Sulphate (Isoprenaline) Following Aortic Valve Homograft Replacement. By LeON RESNEKov, Richard FordhaM, and DonAld Ross

Hæmodynamic Effects of Exercise in Isolated Pulmonary Stenosis Before and After Surgery. By BeNGT Jonsson and SIMON J. K. LEE

Implantable Demand Pacemaker. By Augustin Castellanos, Jr., Louis Lemberg, James R. Jude, Kazi MOBIN-UDDIN, and BAROUH V. BERKOVITS

Natural History of Persistent Ductus Arteriosus. By Maurice Campbell

Electrocardiographic Findings in Patients with Complete Atrio-ventricular Block. By JosE F. LOPEZ

Hæmodynamic Effects of Beta-adrenergic Blockade. By HANs Åström

Left Atrial Function After Electrical Conversion to Sinus Rhythm. By H. IxRAM, P. G. F. Nixon, and T. ARCAN The Frank Vectorcardiogram in Normal Men: Norms Derived from Visual and Manual Measurement of 300 Records. By AlAN F. Lyon and Dino A. Belletti

Absent Sixth Aortic Arch. A Form of Pulmonary Atresia. By Douglas Stuckey, J. D. BowdleR, and R. D. K. Reye Double Outlet Right Ventricle with Long Survival. By H. N. KhatTri, K. P. MisRA, and B. N. Dutta

Double Aortic Arch Associated with Complete Transposition of the Great Vessels. By StanLEy M. Higashino and HERBERT D. RUTTENBERG

Subclavian Artery Aneurysm and Idiopathic Cystic Medionecrosis. By VASIL Persaud

Pulmonary Stenosis in the First Year of Life. By W. T. Mustard, S. C. Jain, and G. A. Trusler

Electron Microscopy of the Heart in a Case of Primary Cardiac Amyloidosis. By E. M. Husband and R. LANNigaN

Extracardiac Anastomosis in Coronary Ostial Occlusion. By N. G. SANERKIN

Congenital Mitral Atresia. By Joan Summerell, C. Miller, V. Persaud, and A. Talerman

The Electromyogram of Respiratory Muscles Registered in the Ordinary Electrocardiogram. By PeTER FLEISCHMANN and YaACOV BAR-KhaYiM 